\title{
La construcción del enemigo
}

\author{
Mi mejor enemigo | Alex Bowen | 2005 \\ Cristian Di Renzo* \\ Universidad Nacional de Mar del Plata
}

Recibido: 26 de junio 2016; aprobado: 28 de octubre 2016

\begin{abstract}
Resumen
La historia nos demuestra como la disputa por la soberanía sobre alguna región determinada puede desencadenar las más cruentas guerras basadas en la desconfianza a partir de la creación de una imagen particularmente negativa acerca del "Otro". Esta situación de desprestigio existente entre Argentina y Chile en lo que respecta en cuestiones limítrofes encuentra, desde finales del siglo XIX, momentos de tensión bélica y de relajamiento. En este caso, trabajará específicamente con el film: Mi mejor enemigo dirigida por Alex Bowen y estrenada en junio de 2005. En esta premiada película de co producción chilena-argentina-española se efectúa una crítica directa al conflicto que tuvo en pie de guerra a Argentina y Chile por el Canal de Beagle y las islas Picton Lennox y Nueva. Más precisamente, la historia transcurre en diciembre de 1978, momento en el cual el inicio de las hostilidades parecía inminente e irreversible y en donde aparecen claramente dos posiciones contrapuestas: la paz o la guerra en donde interviene un concepto clave: la frontera.
\end{abstract}

Palabras clave: Frontera | Similitud-Diferencia | amigo/enemigo

The construction of the enemy

\begin{abstract}
History shows us how the dispute over sovereignty over any given region may trigger the bloodiest wars based on mistrust from creating a particularly negative image about the "Other". This situation existing between Argentina and Chile disrepute with regard to border issues is, from the late nineteenth century, war moments of tension and relaxation. In this case, it will work specifically with the film: My Best Enemy directed by Alex Bowen and released in June 2005. In this award-winning film co Spanish Chile-Argentina-production critical direct conflict took on a war footing is made Argentina and Chile over the Beagle Channel and the islands Lennox and Nueva Picton. More precisely, the story takes place in December 1978, at which time the outbreak of hostilities seemed imminent and irreversible and where two opposing positions appear clearly: peace or war where it intervenes a key concept : the border.
\end{abstract}

Keywords: Similarity | Difference | Border | friend-enemy

\section{Contexto histórico y análisis del film}

"La conciencia territorial es un don de convergencia entre los determinantes históricos y los conocimientos geográficos en el plano de la realidad, y se manifiesta como una expresión de la madurez espiritual de un pueblo, cuando se ha formulado la conciencia nacional en el marco del Estado-Nación”. ${ }^{1}$

Esta idea era ampliamente compartida por varios de los militares más reacios a las negociaciones que creían que una pérdida territorial no era otra cosa que una derrota moral y para algunos eso era inaceptable. El devenir de los sucesos va a estar condicionado por el peso de algunos de los militares involucrados que van a ir obstaculizando o favoreciendo el desarrollo de los acontecimientos. En el caso del litigio por el Canal de Beagle y las islas Picton Lennox y Nueva, las incidencias que tienen las estructuras decisorias y el tipo de régimen particular influyen sobre los procesos de negociación diplomática. ${ }^{2}$

Los conflictos entre los Estados pueden producirse debido a diversos motivos y desde diferentes perspectivas analíticas. ${ }^{3}$ Ahora bien, se optará por una perspectiva en particular, en la cual se pueden identificar varios elementos representativos para-con el conflicto. Si consideramos la naturaleza del desenlace de los conflictos entre los Estados, podemos diferenciar al menos tres tipologías: "luchas", "juegos” y "debates". ${ }^{4}$ Las "luchas", tipos de conflictos casi automáticos, es la categoría que mejor

* cristiandirenzo1@gmail.com 
ilustraría la escalada de violencia pre bélica entre Argentina y Chile para el periodo 1977-1978. Es así que podemos observar que los gastos militares como porcentaje del P.B.I. presentan un notable aumento en Argentina a partir de 1976 y se mantienen relativamente similares en los años posteriores hasta el retorno de la democracia. Conclusiones similares pueden obtenerse en el análisis de los gastos chilenos. ${ }^{5}$

En ese tipo de conflicto, las acciones de una de las partes propician el accionar contrario del otro existiendo procesos de aceleración o de desaceleración. Esto puede evidenciarse, la aceleración, en las carreras armamentísticas de cada país. Particularmente, para el caso argentino, las crecientes exportaciones facilitaron la acumulación de reservas en efectivo que prepararon el camino para algo muy similar a una "orgia" de compras en el mercado de armamentos del mundo, compras desenfrenadas que se aceleraron en los últimos meses de $1978 .{ }^{6}$

Sin embargo, un dato central de esta situación está dado en que tanto en Argentina como en Chile existían regímenes autoritarios que llegaron al poder de la mano de Golpes cívicos-militares y se pretendió fomentar además, por las posiciones más duras, una deshumanización acerca del otro. Esto último sería una condición necesaria para fomentar el odio necesario para iniciar las hostilidades hacia su propio vecino.

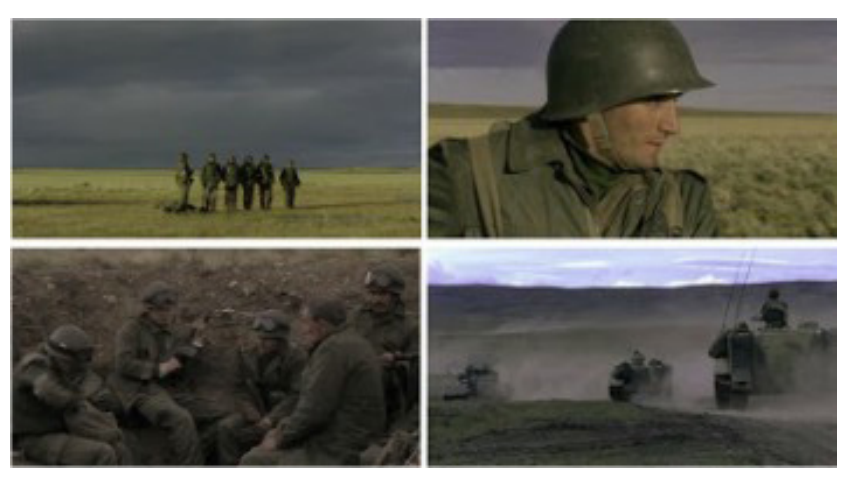

Es en este sentido en el que en el film se presenta el dilema existente entre dos universos irreconciliables: en primer lugar la posición más dura ligada a la inevitabilidad de la guerra expresada en las facciones ligadas al nacionalismo territorialista, en donde se fomentaba el odio y en la que se sustentaban derechos de posesión desde ambos lados a través de múltiples elaboraciones teóricas. Además, bajo esta óptica, se considera al otro como un enemigo, diferente, al que hay que vencer bajo cualquier costo. En segundo lugar se expresa la opción contraria, en donde se apostaba a una salida pacífica del conflicto y en donde reinaban expresiones que se enlazaban más en las similitudes existentes entre ambos países. Varios son los momentos en los que el film incurre en esta dicotomía y en la incomodidad de tener que apuntar las armas frente a un "otro" que es diferente pero a la vez es familiar, similar, en el sentido del mutuo reconocimiento como un igual. Se tomará el ejemplo del sargento chileno Osvaldo Ferrer quien en el momento de responder como es Argentina el mismo responde "igual que aqui" y además deja en claro que en la región en la que están inmersos las familias están compuestas por ciudadanos de ambos países. Aun así, la posición del sargento quien tenía pleno conocimiento del aspecto social de la región, está dispuesto a apuntar su fusil, aunque esta situación puede analizarse también en el hecho del respeto de la estructura jerárquica dentro de la Fuerza a la que pertenece y la mera oposición a la orden impartida desde arriba, implicaría una situación de desobediencia y conllevaría un castigo.

Otro de los aspectos en los que el film incurre también es en exponer la situación que les tocó vivir a los jóvenes que estuvieron involucrados en la puesta en marcha de los preparativos para el enfrentamiento bélico desde ambos bandos. ${ }^{7}$ La voz en off del soldado chileno, en momentos en los que su grupo pierde referencia a raíz de la descomposición de una brújula, apunta claramente a describir que "las trincheras son para esconderse, nosotros solo queríamos que alguien nos encontrara". Tal vez, uno de los aspectos a destacar es que el servicio militar tenía el carácter de obligatoriedad en ambos países y por lo tanto a las fracciones que les tocó incurrir en servicio para 1978, tuvieron que formar parte de los planes de ataque y defensa correspondientes. Se reflejan rasgos claves relacionados con la juventud en ambos bandos, en donde por ejemplo, prevalecía la pasión por el fútbol, deporte por excelencia de la región del atlántico sur. De hecho, el mundial de 1978 va a tener una importante función legitimadora de la dictadura en Argentina ${ }^{8}$ y se intentó dar una imagen de pacificación y de orden hacia el mundo debido a que las denuncias y los reclamos por justicia en relación a los detenidos desaparecidos habían tenido repercusiones a nivel internacional. Es así que los jóvenes encuentran en un partido de futbol la canalización de la necesidad de diversión en medio de un clima bélico, aunque el mismo no está exento de tensiones, estrechamente ligadas con los sujetos más "profesionales", con una clara tendencia 
nacionalista. Además el juego les permite escapar del miedo a la muerte que existía dentro de estos jóvenes a sabiendas de la cercanía de ella. En este sentido, es pertinente nombrar la escena en la que los conscriptos bailan entre ellos las danzas típicas de cada país: el tango en Argentina y la cueca en Chile. Esto último constituye una parte importante en la construcción de las identidades culturales de cada país y actuaría a la vez, como un elemento de diferenciación entre ellos.

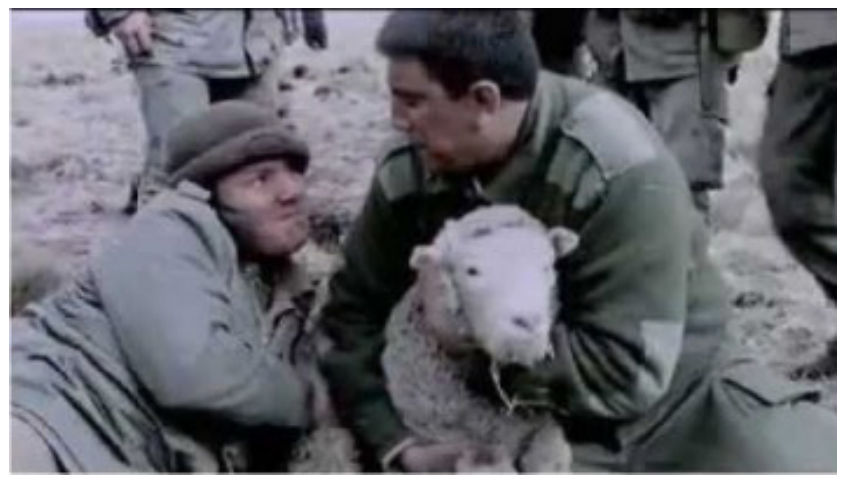

Ahora bien, una escena disruptiva es la que sucede tras la aparición de un pastor quien circula libremente por esas tierras y no le preocupa para nada la delimitación de la frontera. El término de frontera ${ }^{9}$ puede analizarse desde múltiples puntos de acceso: como un límite físico que marca una diferencia política, aunque no cultural entre dos países o bien como un límite cultural, social o ideológico generado por las culturas para marcar aquello que es correcto y aquello que se aleja de la normalidad aceptada. ${ }^{10}$ Es por ello que la demarcación "simbólica" de la frontera, por parte de los soldados adquiere un significado claramente asociado a una situación ineludible: la necesidad de demarcar una diferencia en una zona en donde predominan las similitudes, ya sean geográficas, culturales y hasta históricas entre ambos países. Es por ello que en este trabajo se considera que la frontera existente a través de la cordillera de Los Andes no es más que una frontera políticamente delimitada, cuyos orígenes legales surgen hacia finales del siglo XIX, momento de consolidación de los diferentes Estados-Naciones en América Latina y en gran parte del mundo occidental. Es más, se puede observar que las regiones en cuestión están íntegramente relacionadas producto de la historia compartida y de la cercanía geográfica. En este sentido, el film es claro: la lógica de amigo-enemigo es absurda y se refleja en otra situación clave: la herida del conscripto chileno Guillermo Mansilla. Al no poseer medicina, surge el debate moral de solicitar ayuda a los soldados argentinos quienes en la inmensidad del territorio que los rodea, serían los únicos que tendrían la posibilidad de salvarle la vida, aunque también son quienes podrían quitársela. La situación se resuelve con el intercambio solidario de ambos bandos. Justamente a es través de "brújula", una perra que encuentran perdida, es que se inician las relaciones entre ellos. No obstante, el soldado más profesional argentino opuso resistencia a que se le brinde la ayuda necesaria, puesto que "no hay mejor chileno que un chileno muerto", a lo que su superior Ocampo le responde rápidamente "silencio, y usted no sea bestia". Otra escena en la que refleja tal dicotomía, es la representada por el soldado más intransigente chileno que no aceptó comer el cordero que les había regalado aquel pastor que se encontraba de paso, alegando que no podía hacer tal cosa con el enemigo; a su vez le pregunta a su superior Ferrer ¿usted cree que van a poder matar tan fácil después de esto?, a lo que este le responde "hay cosas que uno hace que no sabe por qué las hace y esta es una de esas". Sin embargo el soldado no acepta ir y resta solo limpiando su rifle. Estos casos demuestran nuevamente la lógica del título Mi mejor enemigo.

A raíz del análisis de las situaciones expresadas podemos sostener que el film refleja un concepto de frontera que se asemeja más a su concepción como un espacio de intercambio e interconexión entre dos culturas que son ante todo similares, con raíces comunes pero que han ido desarrollando, a lo largo de la historia particularidades, diferencias entre ellas.

Sin embargo, al transcurrir dentro de un sistema jerárquico de dominación propio de las FF.AA., en el momento en el que la guerra es inminente, el 22 de diciembre, los bandos que habían jugado, bailado e intercambiado horas de sus vidas, se preparan para abrir fuego unos contra otros, como si fueran desconocidos. Finalmente, con la llegada de la noticia del cese de la hipótesis de guerra por medio del radio de los argentinos se vive un instante de alegría y distención hasta el momento en el que Ocampo se acerca a devolver las cartas que le había confiado un conscripto chileno. Contrariamente, el bando chileno no había recibido las órdenes de replegarse puesto que su radio no tenía batería, por lo cual se termina con un intercambio de disparos iniciado por el soldado "más profesionalizado" chileno y que tendrá como resultado un herido y un muerto. Se efectiviza, entones, la creación imaginaria del otro, puesto que toda guerra contiene en sí misma un componente imaginario por más fundamentos teóricos que puedan esbozarse con mayor o menor claridad. 


\section{Conclusiones}

El film toma el nombre de $M i$ mejor enemigo a partir del hecho de mostrar diversas situaciones en donde entran en tensión la asimilación con la diferenciación entre ambos bandos. Pese a que las similitudes son mayoría frente a las diferencias, la tensión de una guerra inminente, inevitable, pone de manifiesto como la estructura decisoria hacia el interior de las FF.AA. con el particular contexto histórico que presentaba para ese entonces dos gobiernos dictatoriales podía desencadenar sin demasiados contratiempos el inicio de las hostilidades. Incluso, al inicio del film, el soldado conscripto Rojas deja constancia de la existencia de desaparecidos en su tierra, situación en la que lamentablemente existían también, similitudes hacia ambos lados de la cordillera y con algunos matices, en varios países limítrofes.

También podrían interpretarse que los planos realizados para poder contemplar la región en la que transcurre gran parte de la película, tendrían la intencionalidad de mostrar otro aspecto importante, la sensación de soledad con la que debían convivir estos jóvenes que debieron incurrir a un enfrentamiento contra otros jóvenes con los que se identifican casi en su plenitud. Incluso en ese inmenso territorio de la pampa patagónica, unos y otros no logran diferenciarse, son sólo un componente más del paisaje que no distingue diferencias. La aparición del pastor quien circula libremente por esos pagos, no hace otra cosa más que reflejar tal situación, ingenua y ridícula, pero real. Es en este sentido que el concepto de frontera adquiere una importancia central ya que el origen de tal delimitación se puede encontrar ante la necesidad de “protección” ante lo extraño, lo ajeno y que por lo tanto puede ser considerado como hostil y peligroso. En este sentido, el Estado a través de sus FF.AA. sería el encargado de controlar y contener tal frontera, ${ }^{11}$ tan precisa $\mathrm{y}$ tan confusa a la vez.

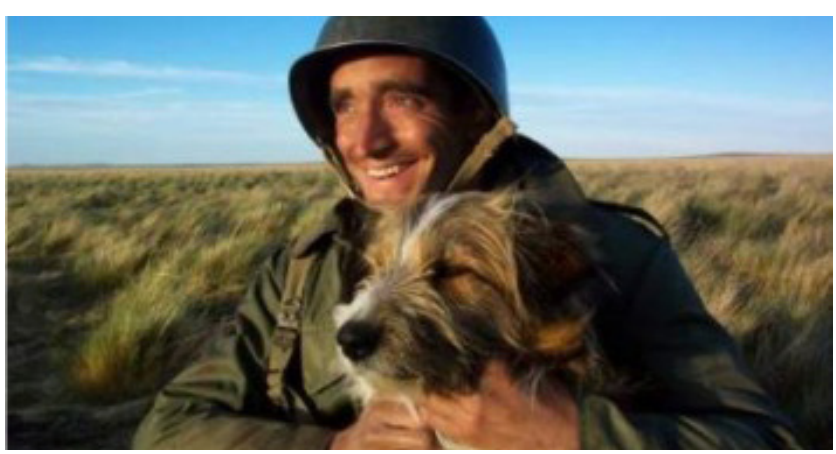

Las situaciones de diversión entre los jóvenes es un elemento disruptivo que en cierta parte contribuye a fortalecer la posición por la paz frente a la postura belicista, aunque momentáneamente, ya que el film incurre en intercalar momentos de tensión con otros de relajamiento. Aun así la juventud vence el miedo a morir en los momentos de diversión entre ambos. En este sentido, la aparición de la perra podría interpretarse como una señal de humanidad por parte de los soldados frente a la pretendida deshumanización impartida desde arriba por dos regímenes militares, ya que no se podría apuntar y disparar hacia el otro sin antes crear una imagen negativa del adversario.

Al finalizar el film se deja al público una reflexión que nace a partir de Rojas, quien luego del retorno de la frontera se sienta en la mesa con sus compañeros, y brindan por la memoria del conscripto Chilote, abatido en el intercambio de disparos y se desprende casi inevitablemente un razonamiento: " ni un besito, ni un billetito, ni medalla, ni las gracias." A decir verdad, la soledad, única compañera de la travesía que les había tocado vivir, no los había abandonado aun al momento de su regreso. Pues, la sociedad de ambos lados de la cordillera estaba, en su amplia mayoría, exenta, al margen del conflicto limítrofe que los tuvo en pie de guerra y que recibieron a las fiestas de fin de año de 1978 con una sensación de paz, de tranquilidad, tal vez no de ir a la guerra, sino de enfrentarse con quienes convivían desde su nacimiento.

\section{Referencias}

A.A.V.V. (2011) La frontera argentino-paraguaya ante el espejo. Porosidad y paisaje del Gran Chaco y del Oriente de la República del Paraguay. Universitat de Barcelona, Barcelona.

Bosoer, Fabián (2005) Generales y Embajadores. Una historia de las diplomacias paralelas en la Argentina. Bergara. Buenos Aires.

Deutsch, Karl (1974), El análisis de las relaciones internacionales. Psicología. Paidós, Buenos Aires.

García Targa, Juan (2006) Fronteras coloniales en América. El caso de México. Pp. 60. En: Montserrat Ventura i Oller Ariadna Lluís i Vidal-Folch Gabriela Dalla Corte Ed. (2006) La Frontera entre limits i points, Casa América Catalunya, Barcelona.

Madrid Murúa, Rubén (2003) “La Estrategia Nacional y Militar que planificó Argentina, en el marco de una estrategia total, para enfrentar el conflicto con Chile el año 1978”, Memorial del Ejército de Chile, Edición No 471, págs. 50-69, Santiago, Chile.

Mosquera, Carlos Julio (1994) La conciencia territorial argentina. Círculo Militar Argentina. Buenos Aires. 
Oszlak, Oscar. (1987) La formación del Estado argentino: orden, progreso y organización nacional. Planeta Buenos Aires. Passarelli, Bruno. (1998). El delirio armado. Argentina-Chile. La guerra que evito el Papa. Sudamericana. Buenos Aires. Stepan, Alfred. (1982) Repensando a los militares en política. Cono Sur: Un análisis comparado. Sudamericana/ Planeta S.A. Buenos Aires.

Tulchín, Joseph (1990) La Argentina y los Estados Unidos. Historia de una desconfianza. Planta. Buenos Aires.

1 Daus Federico 1978; 169. En Mosquera, Carlos Julio (1994) La conciencia territorial argentina. Círculo Militar Argentina. Buenos Aires.

2 Bosoer, Fabián (2005) Generales y Embajadores. Una historia de las diplomacias paralelas en la Argentina. Vergara. Buenos Aires.; 327.

3 Las distintas perspectivas de análisis ligadas a temáticas pertenecientes a las Relaciones Internacionales están determinadas por las distintas tradiciones de pensamiento y los grandes paradigmas teóricos. Sin embargo, el panorama actual presenta una gran diversidad de enfoques que presentan un pluralismo teórico y metodológico dentro de la disciplina.

4 Rapoport 1960 en: Deutsch, Karl (1974), El análisis de las relaciones internacionales. Psicología. Paidós. Buenos Aires.

5 Stepan, Alfred. (1982) Repensando a los militares en política. Cono Sur: Un análisis comparado. Sudamericana/ Planeta S.A. Buenos Aires pp. 77.

6 Tulchín, Joseph (1990) La Argentina y los Estados Unidos. Historia de una desconfianza. Planta. Buenos Aires. Pp 261.

$7 \quad$ En el caso argentino, se desplegó el denominado Operativo Soberanía. Al respecto véase: Madrid Murúa, Rubén (2003) “ $L a$ Estrategia Nacional y Militar que planificó Argentina, en el marco de una estrategia total, para enfrentar el conflicto con Chile el año 1978”, Memorial del Ejército de Chile, Edición No 471, págs. 50-69, Santiago, Chile.

8 De hecho, el conflicto era vivido por algunos militares argentinos en términos similares al de un partido de futbol en donde el empate de por sí era una derrota. Al respecto véase Passarelli, Bruno. (1998). El delirio armado. Argentina-Chile. La guerra que evito el Papa. Sudamericana. Buenos Aires.

$9 \quad$ Un análisis pormenorizado del concepto de frontera puede obtenerse a través de la obra: A.A.V.V. (2011) La frontera argentino-paraguaya ante el espejo. Porosidad y paisaje del Gran Chaco y del Oriente de la República del Paraguay. Unversitat de Barcelona. Barcelona.

10 García Targa, Juan (2006) Fronteras coloniales en América. El caso de México. Pp. 60. En: Montserrat Ventura i Oller Ariadna Lluís i Vidal-Folch Gabriela Dalla Corte Ed. (2006) La Frontera entre limits i points, Casa América Catalunya, Barcelona.

11 En relación a la consolidación estatal véase Oszlak, Oscar. (1987) La formación del Estado argentino: orden, progreso y organización nacional. Planeta Buenos Aires. 